\title{
REMOVAL AND RECOVERY OF HALOTHANE AND METHOXYFLURANE FROM WASTE ANAESTHETIC: VAPOURS
}

\author{
J. W. R. MCINTYRE, F.F.A.R.C.S., AND J. C. RuSSELL, PH.D. ${ }^{*}$
}

ETher vapour has an irritant quality and is considered by many people to have an unpleasant odour. This constituted a problem for pioneers of anaesthesia, and among the various ways in which induction was modified was the addition of odoriferous substances to the ether vapour. Numerous agents were employed for this purpose including mint, oil of wintergreen, camphor, musk, and oil of cloves. ${ }^{1}$ Gwathmey was apparently in the habit of preceding the anaesthesia by inhalation of a vapour of eau de Cologne or whiskey from one bottle of a three-bottle apparatus he customarily employed. He later used oil of Bergamot, a citrus fruit with a lemon-like odour, or terpinol, a synthetic compound smelling like lilac, but oil of bitter orange was considered superior to these other substances. ${ }^{2}$ It was reputed to mask the smell of the anaesthetic for the patients and the occupants of the operating room as well. The mechanism of action was unknown, though it was suggested that the function of olfactory and trigeminal nerves was impaired or that a psychological effect occurred, and the state was referred to in the medical literature of the time as the "Mystery of Ether Anaesthesia."3 Though described with enthusiasm, the practice does not seem to have been widely used, and no further references of this nature were made until Hewer described the scenting of ethyl chloride with a chemical substance giving it an odour resembling eau de Cologne. ${ }^{4}$ The decrease in interest in this subject is probably due to a variety of factors including the use of intravenous drugs, closed or semi-closed systems of administration, effective air conditioning, and halogenated hydrocarbons whose odour is not universally considered unpleasant. However, the odour of an agent does play a part in its acceptance by operating room personnel until olfactory adaptation occurs, whether this is due to fatigue on a highly specific basis or a more central occurrence akin to gating in the auditory pathways. A more pertinent problem is the use of these agents in the poorly ventilated environment with which emergency surgery may perhaps be associated. In addition the possibility that inhalational anaesthetic drugs may have chronic toxic effects on the administrator has been suggested, ${ }^{5}$ and, although instances of dangerous qualities being attributed to unpleasant odours are not unusual, a case in which an anaesthetist may have been sensitized to the drug has been reported. ${ }^{6}$ Thus it seemed of interest to study the efficacy of a commonly used adsorbentcarbon granules-for removal of halothane and methoxyflurane from vented anaesthetic vapours.

\section{METHOD}

Vapour phase chromatography is a widely used method of analysis for chemical compounds with an appreciable vapour pressure. The merits of the technique are

\footnotetext{
"Department of Anaesthesia and Department of Chemistry, University of Alberta, Edmonton, Alberta.
} 
reasonable accuracy combined with speed of analysis and the ability to analyse complex mixtures. In essence the method consists of injecting a sample into a gas stream which carries it through a column packed with a suitable adsorbent material. The different constituents of the sample are adsorbed to differing degrees and thus retarded by varying amounts in their passage through the column. If a suitable column packing has been chosen the sample constituents will emerge separately. Various methods for detection of the eluted constituents are available, the simplest being a thermal conductor detector. This method has previously been applied to the measurement of volatile anaesthetic agents, and Zander et al. ${ }^{7}$ have presented a detailed discussion of vapour phase chromatographic techniques.

In the work presented here the column packing used was DS 710 silicone oil on a firebrick support at $85^{\circ} \mathrm{C}$. A thermal conductivity detector fitted with tungsten filaments was employed to detect the eluted peaks. The carrier gas was helium. A $1.0 \mathrm{ml}$. gas-tight syringe, Hamilton no. $1001 \mathrm{CN}$, fitted with a hypodermic needle, gauge 20 , was employed to inject $0.5 \mathrm{ml}$. vapour samples directly on to the column through a silicone rubber seal. Vapour standards were prepared in one-litre glass flasks sealed with a rubber serum cap. An appropriate volume of liquid methoxyflurane or halothane was introduced with a microlitre syringe which was calibrated by weighing. The standard vapour samples were allowed to reach equilibrium, and $0.50 \mathrm{ml}$. aliquots were injected in the same manner as that used for the pre- and post-adsorber samples. Chromatographic measurements over a period of six hours showed that vapour was not absorbed by the rubber cap to an extent that was significant in these experiments. Injection of liquid methoxyflurane or halothane in quantities of $1 \mu \mathrm{l}$. directly on to the column gave a highly reproducible and very sharp peak. However, it was found that use of the area of this peak for calibration purposes would give large errors in the absolute vapour concentration measured. Nevertheless, liquid injection is very fast and provides a useful check on the stability of the instrument.

Methoxyflurane and halothane were vaporized by pumping air with a Harvard ventilator, or passing oxygen from a cylinder and flowmeter through a Pentec vaporizer specially calibrated by the manufacturer or through a Fluotec vaporizer. Activated cocoanut charcoal (Fisher Scientific Co. 5-685 Mesh 6-14) was placed in cylindrical containers (Foregger infant soda-lime canisters), approximately $7.3 \mathrm{~cm}$. long by $4.4 \mathrm{~cm}$. in diameter or $11 \mathrm{~cm}$. long by $5 \mathrm{~cm}$. in diameter, containing $50 \mathrm{gm}$. or $125 \mathrm{gm}$. of granules respectively. When in use the cylinder was suspended vertically and connected directly to the vaporizer. During desorption, heat was applied by immersion in a water bath, the necessary precautions being taken to prevent water entering the canister.

A glass tube $25 \mathrm{~cm}$. long and $2 \mathrm{~cm}$. in diameter was connected to the adsorber outlet. Vapour sampling was taken proximal to the adsorber and through a minute silicone-rubber-covered orifice in the side of the glass tube immediately distal to the adsorber outlet.

\section{Results}

Figure 1 shows the effect of the smaller adsorber on the concentration of methoxyllurane in the oxygen stream emerging from the vaporizer under various 
conditions. It will be noticed that all curves show an initial region where only a trace of the drug passes through the adsorber. After a period of time which depends on the flow rate of the gas stream, the drug concentration, and the character of the flow, there is a rapid rise in the amount of methoxyflurane which rapidly approximates the pre-adsorber concentration.

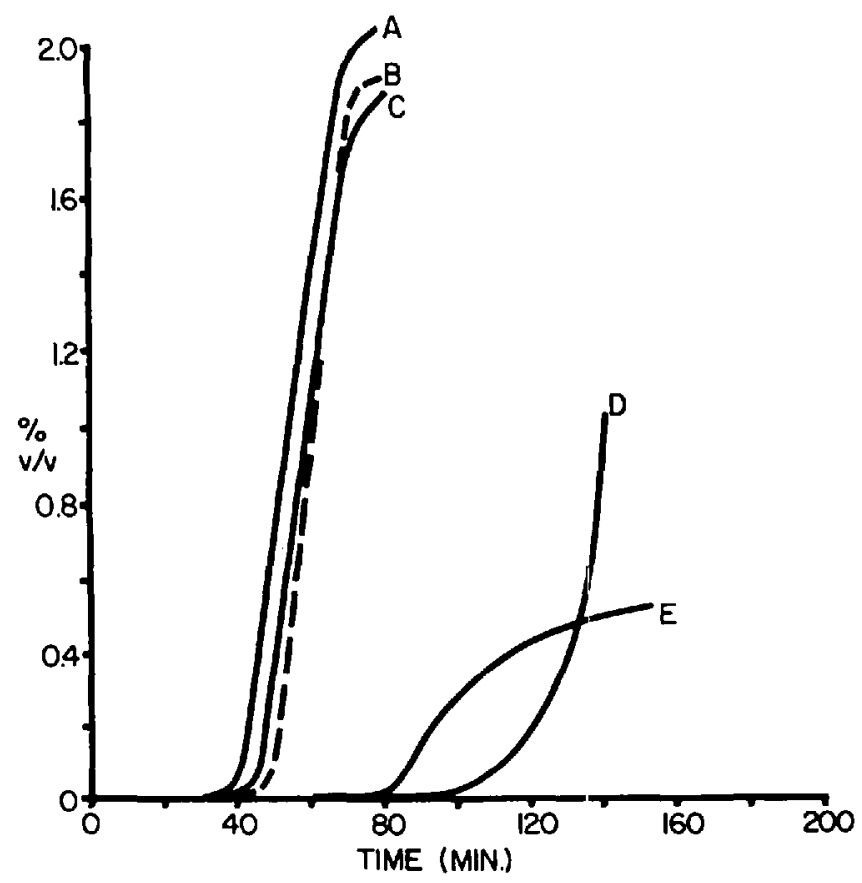

Figuhe 1. Concentration of methoxyflurane in gas emerging from adsorber containing approximately $50 \mathrm{gm}$. of adsorbent. A: oxygen 2 L./min., Pentec dial setting 1.5. B: oxygen 2 L./min. (humidified), Pentec dial setting 1.5. C: oxygen 4.5 L./min., Pentec dial setting 1.5. D: oxygen $4.5 \mathrm{~L} . / \mathrm{min}$., Pentec dial setting 0.5 . E: oxygen 100 c.c. $\times 20 / \mathrm{min}$. using Harvard animal ventilator, Pentec dial setting 0.5 .

Figures 2 and 3 illustrate the results obtained when the larger adsorber was employed with methoxyflurane or halothane vapour. They also show the concentration of halothane or methoxyflurane delivered from the adsorber when heat was applied to it and a gas stream passed through it. When the adsorber was weighed, it was found that not all the drug had been revaporized at the termination of these experiments and when used subsequently the adsorbent efficiency of the charcoal had been considerably reduced.

During the course of these experiments it was noted that there was some variation between the dial settings of the vaporizers and the delivered quantities of the drug. At a $10 \mathrm{~L} . / \mathrm{min}$. oxygen flow at a dial setting of 3 per cent, the Fluotec had an output of 2.4 per cent which fell to 2.1 per cent after one hour of operation.

The output of the Pentec vaporizer was measured at different dial settings and oxygen flows of $2 \mathrm{~L}$. $/ \mathrm{min}$. and $4.5 \mathrm{~L}$./min. The instrument had previously been 


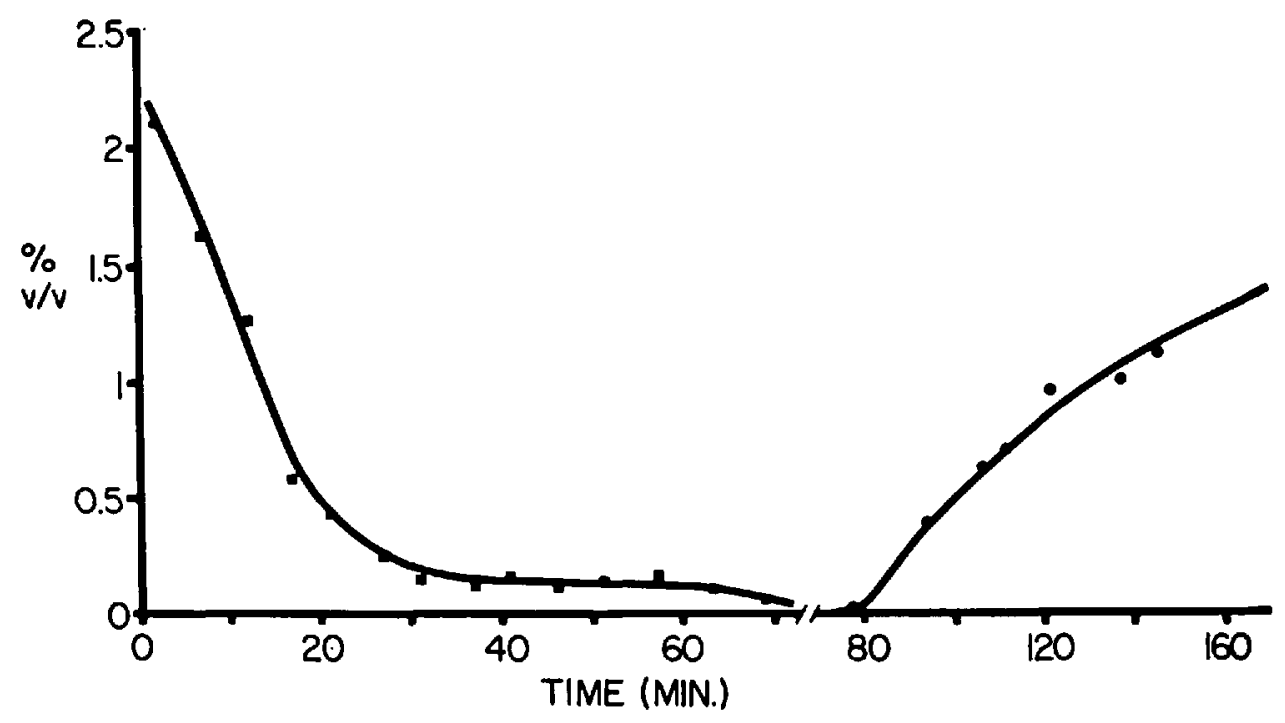

FIGURE 2. Removal and recovery of methoxyflurane from approximately $130 \mathrm{gm}$. of adsorbent represented as the gradual appearance of methoxyflurane in effluent air after 75 minutes of almost complete adsorption from the inflow supplied at 200 c.c. $\times 20 /$ minute by a Harvard animal ventilator, Pentec setting 1.5, and the recovery of methoxyflurane from the saturated adsorbent when air was similarly supplied and the adsorbent and container immersed in a water bath at $75^{\circ} \mathrm{C}$.

calibrated at $4.0 \mathrm{~L}$. $/ \mathrm{min}$. by the suppliers. The values determined and the suppliers' figures are shown in Table I, and these are in substantial agreement. However, this output was found to decrease slowly as the vaporizer was operated. At $2 \mathrm{~L} . / \mathrm{min}$. and 1.5 per cent dial setting the output exceeded 1.5 per cent, being within the range 1.6-2.4 per cent. At 0.25 per cent dial setting the output fluctuated in an apparently cyclical fashion over a range of $0.1-0.4$ per cent. The environment in which the measurements were done was similar on each occasion but samples were taken after varying periods of vaporizer use.

\section{Discussion}

There exists a variety of possible mechanisms for protecting operating room personnel from the odour of vented anaesthetic vapours, and these can be categorized as: (a) inactivation of olfactory receptors; (b) alteration of the odour; $(c)$ removal of the odour from the vicinity; $(d)$ removal of the odorous substance at its site of release.

The mechanism of olfaction has not been fully elucidated, but any attempt to blockade olfactory receptors seems impractical and inadvisable. Odour masking is the process of obliterating one odour by superimposing another more pleasant sensation. The agent does not alter the composition of pre-existing odours, thus constituting an aromatic correction, but has an action at the point of perception. Odour cancellation refers to the antagonism of one odour with another so that the end result is a complete absence of smell, while odour neutralization is the reaction 


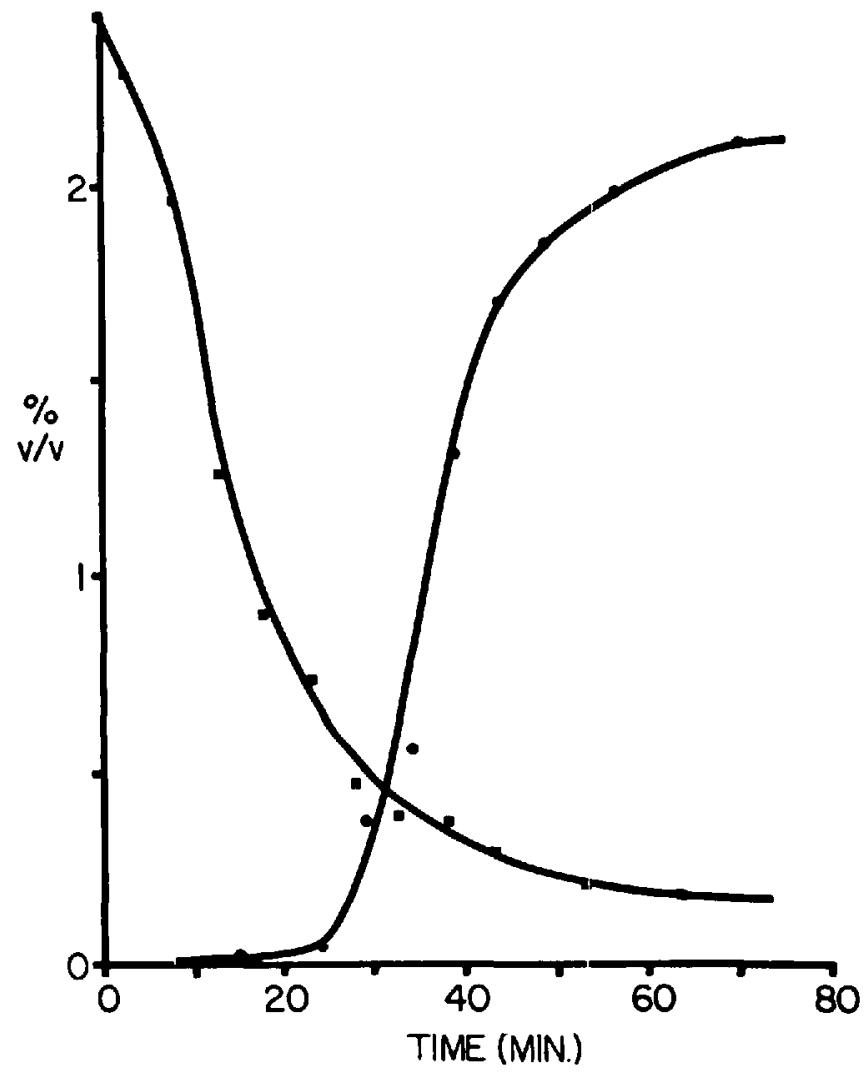

FIGURE 3. Removal and recovery of halothane from approximately $130 \mathrm{gm}$. of adsorbent, represented as the gradual appearance of halothane in effluent oxygen after 1.5 minutes of almost complete absorption from a $10 \mathrm{~L}$./min. oxygen inflow, Fluotec setting 3.0, and the recovery of halothane from the saturated adsorbent, oxygen supplied at $4 \mathrm{~L} . / \mathrm{min}$. through the adsorbent immersed in a water bath at $67^{\circ} \mathrm{C}$.

TABLE I

\begin{tabular}{ccccc}
\hline & & & \multicolumn{2}{c}{ Supplier's calibrations at $70^{\circ} \mathrm{F}}$. \\
\cline { 4 - 5 } Dial setting & $2 \mathrm{~L} . / \mathrm{min} . \mathrm{O}_{2}$ & $4.5 \mathrm{~L} . / \mathrm{min} . \mathrm{O}_{2}$ & $4 \mathrm{~L} . / \mathrm{min} . \mathrm{O}_{2}$ & $5 \mathrm{~L} . / \mathrm{min} . \mathrm{O}_{2}$ \\
\hline 1.5 & 1.80 & 1.39 & 1.44 & 1.47 \\
1.0 & 1.08 & 0.74 & 0.84 & 0.94 \\
0.5 & 0.57 & 0.24 & 0.47 & 0.51 \\
\hline
\end{tabular}

in the air of two odoriferous substances to produce an odorless one. These methods are employed in many commercially available "deodorizers."

The removal of explosive anaesthetic vapours from the site of release has for many years been achieved by means of suction, but this is a noisy and sometimes inconvenient method. A simpler and equally effective way of dealing with nonflammable vented anaesthetic vapours is the use of a low-resistance modification of the exhalation valve. The attachment to this modification of a standard 
length of corrugated tubing permits release of the gases at floor level. Many artificial ventilators discharge excess gases directly toward the ground.

Activated carbon granules have been extensively used in the adsorption of chemical compounds. The adsorptive characteristics depend on the source of the carbon, cocoanut being the most satisfactory, and the mode and degree of activation. The term activation refers to the high temperature release of the slightly volatile impurities that remain in charcoal. Within the activated carbon granules are cavities and capilliaries, and the aggregate surface area of a cubic inch is estimated to be approximately five acres. Unlike many adsorptive agents such as silicagel, carbon will release water vapour in preference for odorous vapours or gases. This has obvious advantages for the purpose described here, and in clinical use the humidity of exhaled vapours did not appreciably effect the performance of the adsorber.

The mechanical factors affecting the passage of a gas through an adsorber have been extensively studied in relation to carbon dioxide elimination by Adriani and his colleagues. ${ }^{8}$ These factors are applicable to the present process but this differs from the soda-lime-carbon-dioxide system in that it is a physical process of adsorption and not a chemical process of absorption. The shape of the adsorption curves in Figures 1 to 3 is to be expected. Initially the carbon granules can adsorb all the drug in the gas stream. Provided the rate of input is reasonably low the granules will adsorb until they become saturated, whereupon the concentration in the effluent stream will rise rapidly. If the rate of input is very high, then the granules will become less efficient and adsorb less before showing saturation effects.

The capacity of the carbon granules for adsorption of the drug may be expressed in terms of the produce of the gas flow before saturation takes place and the quantity of drug in the gas, and in units of litres per cent. The capacity of the $50 \mathrm{gm}$. charge used in the manner described varied between 200 and $350 \mathrm{~L}$. per cent. The capacity was greater at high flow rates, suggesting that pattern of gas flow through the adsorber has an influence on the effective quantity of carbon granules and that granule migration occurs as is the case with sodalime. ${ }^{3}$ A capacity of $200 \mathrm{~L}$. per cent for a $50 \mathrm{gm}$. charge corresponds to absorption of approximately $25 \mathrm{gm}$. of methoxyflurane. This is in agreement with the weight increase found for the adsorbent.

The adsorption of halothane and methoxyflurane in this fashion appears to have little place in the usual practise of anaesthesia. However, when closedcircuit systems are not practicable and anaesthetics are used in confined situations, the use of a cheap and readily available adsorption technique such as described here may well be of value. The desorption curves shown in Figures 2 and 3 indicate that what might be a useful quantity of an expensive drug can be recovered. The significance of this depends upon the economic situation of the user as well as the availability of unused drugs. However, attention must be drawn to the possible transmission of infection, though it seems likely that the granules would act as a filter for all but the smaller organisms. In addition, though it is unlikely that contaminants with which the drug can react exist with the carbon granules, nevertheless in the absence of thorough studies such an assumption should not be made. 
In conclusion, operating room personnel can be spared the odour of anaesthetic vapours in a variety of ways including low-flow semi-closed systems, direction of effluent vapours toward the floor, and appropriate use of existing operating room ventilation systems. In addition, canisters of activated carbon granules are effective in removing halothane and methoxyflurane from effluent vapours. Their use may be of value during anaesthesia in certain situations, e.g., in confined locations or in the absence of adequate ventilating systems.

\section{SUMMARY}

The odours of anaesthetic vapours may play a part in drug acceptance by operating room personnel, and it has been suggested by others that they may constitute a health hazard. The methods of disposal of waste anaesthetic vapours have been briefly considered. The results of vapour chromatographic studies show that activated carbon granules adsorb halothane and methoxyflurane. It is suggested that this may have a clinical application under certain situations, as in confined locations or in the absence of adequate ventilating systems.

\section{RÉSUMÉ}

L'odeur des vapeurs anesthésiques peut jouer un rôle dans la faveur accordée à un produit par le personnel de la salle d'opération; d'autres ont pensé que ces odeurs peuvent être dangereuses pour la santé. On a examiné brièvement les manières de se débarasser de l'excédent de vapeurs anesthésiques. Les résultats des études chromatographiques de la vapeur démontrent que des granules de charbon activé absorbent l'halothane et le méthoxyflurane. On émet l'opinion que ceci peut avoir une application clinique dans certaines situations, comme dans des endroits fermés ou en l'absence de ventilation suffisante de la pièce.

\section{REFERENCES}

1. Gwathmey, James T. Anaesthesia. 2nd ed., London: Churchill (1925).

2. Gwathmex, James T. Vapor Anesthesia Apparatus. J.A.M.A. 55: 2150 (1910).

3. Editorial. A Mystery of Ether Anesthesia. New York J. Med. 96: 543 (1912).

4. Hewer, C. Langton. Recent Advances in Anaesthesia and Analgesia. 3rd ed., London: Churchill (1939).

5. Moonie, G. T. \& Williams, R. Tudor. Personal communication.

6. Belfhage, Sven; Ahlgren, Ingemar; \& Axelson, Stig. Halothane Hepatitis in an Anaesthetist. Lancet. 2: 1466 (1966).

7. Zauder, H. L. \& Orkin, L. R. Applications of Gas Chromatography to Anaesthesiology: I. Gases and Vapours. Canad. Anaesth. Soc. J. 10: 228 (1963).

8. Adriani, John. The Chemistry and Physics of Anesthesia. 2nd ed., Springfield: Thomas $(1962)$ 